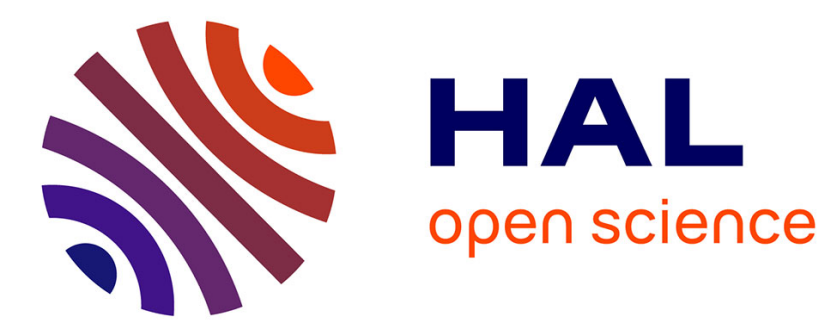

\title{
Nitrate absorption-concentration of Rosa hybrida cv. Sweet Promise grown in soilless culture
}

\author{
Saâdi Bougoul, Richard Brun, André Jaffrin
}

\section{To cite this version:}

Saâdi Bougoul, Richard Brun, André Jaffrin. Nitrate absorption-concentration of Rosa hybrida cv. Sweet Promise grown in soilless culture. Agronomie, 2000, 20 (2), pp.165-174. 10.1051/agro:2000117 . hal-00886001

\section{HAL Id: hal-00886001 https://hal.science/hal-00886001}

Submitted on 1 Jan 2000

HAL is a multi-disciplinary open access archive for the deposit and dissemination of scientific research documents, whether they are published or not. The documents may come from teaching and research institutions in France or abroad, or from public or private research centers.
L'archive ouverte pluridisciplinaire HAL, est destinée au dépôt et à la diffusion de documents scientifiques de niveau recherche, publiés ou non, émanant des établissements d'enseignement et de recherche français ou étrangers, des laboratoires publics ou privés. 


\title{
Nitrate absorption-concentration of Rosa hybrida cv. Sweet Promise grown in soilless culture
}

\author{
Saâdi BougOUL ${ }^{\mathrm{a}^{*}}$, Richard BRUN ${ }^{\mathrm{b}}$ et André JAFFRIN ${ }^{\mathrm{b}}$ \\ ${ }^{\text {a }}$ Unité de Recherche, Laboratoire d'énergie solaire, Université de Batna, Rue Chahid Mohamed El Hadi Boukhlouf, Batna, Algeria \\ ${ }^{\mathrm{b}}$ URIH-INRA, Route des Colles, 06410 Biot, France
}

(Received 15 December 1998; revised 2 December 1999; accepted 16 December 1999)

\begin{abstract}
Recent measurements of transpiration rates and nitrate intakes of young rose plants grown in NFT are confronted with existing models. The water demand is accurately reproduced by the passive leaf evaporation process described by Penman and Monteith (PM model). The mineral demand is tentatively described by Scaife's Pump-LeakBuffer (PLB) model. The PLB model predicts for rose plants, contrary to ryegrass, little phase shift between mineralabsorption and solar radiation; as a consequence, it excludes memory effects from the previous day. But some observed features are not accounted for: the saturation of nitrate reduction rate at high solar radiation, the inhibition of root mineral absorption at high temperature. A modified PLB model (MPLB) is thus proposed, which accurately reproduces nitrate uptake fluctuations under strongly varying climatic conditions. Combining PM and MPLB models enables a modelling of the instantaneous absorption-concentration of nitrates in rose plants. It should then be feasible to manage in real time the composition of the root medium used in soilless cultures, so that neither saline stress nor mineral deficiency could affect plant growth.
\end{abstract}

transpiration / nitrate uptake /absorption concentration / rose plants /models

Résumé - Concentration d'absorption du nitrate de Rosa hybrida cv. Sweet Promise en hors-sol. De récentes mesures de transpiration et d'absorption d'azote nitrique faites sur des jeunes plants de rosier cultivés en NFT, sont confrontées avec des modèles existants. La consommation hydrique est déduite du modèle de Penman-Monteith. Le modèle d'absorption du nitrate est une adaptation du modèle « Pompe - Fuite - Réservoir » de Scaife au rosier en NFT, selon les données expérimentales que l'on possède. Un aménagement du modèle permet de prendre en compte les caractéristiques du rosier. Un modèle de Scaife modifié peut rendre compte des courbes d'absorption observées en NFT en présence de mécanismes perturbateurs (températures excessives et rayonnement saturant). Une combinaison des deux modèles, permet de prévoir la concentration d'absorption d'un rosier à toute heure de la journée. Donc l'adaptation de la solution nutritive à la demande instantanée de la plante est faisable, ce qui permet de soustraire la plante à toute carence minérale ou stress salin.

transpiration / demande nitrique / concentration d'absorption / plants de rosier / modèles

Communicated by Jean-François Ledent (Louvain-La-Neuve, Belgium)

* Correspondence and reprints

s_bougoul@hotmail.com 


\section{Introduction}

Soilless cultural techniques are rapidly gaining momentum in Mediterranean regions, because they solve problems with soil parasites and increase greenhouse productivity. In northern Europe, rising concern about water pollution often percludes drainage of nutrient solutions.

In Mediterranean countries, where environmental pressure is not yet present, crop quality and yields could still benefit from a more rigorous management of fertigation: salinity rises at the root surface, resulting from a strong transpiration demand, can generate plant stress and trigger stomatal closure [10]. A more precise matching of the composition of root media and the actual plant requirements would certainly improve crop quality and yields .

A detailed study of rose plant instantaneous uptakes was performed by one of the authors [5] by using $\mathrm{NO}^{-}$and $\mathrm{K}^{+}$selective probes in a NFT cultural setup placed on a precision balance.

\section{Experimental data on plant absorption}

\subsection{Kinetics of water absorption}

Experimental setup. This consists of a simple weight loss measurement carried out by placing 16 mature rose plants with their own feeding tank on a precision scale $( \pm 1 \mathrm{~g})$. The total radiation $R_{g}$ was measured by a Licor Li200 S2 cell placed very close above the plant canopy. A 30 min time interval separates successive records. Continuous feeding with the recycled nutrient solution is done by a pump.

On a sunny day, the water absorbed by the rose plant can be considered to be almost entirely transpired: the actual weight gain over a $24 \mathrm{~h}$ period is only a small fraction of it (about 2\%). The transpiration rate, shown in Figure 1, follows the pattern of the radiation $\mathrm{R}_{\mathrm{g}}$. At night, a reduced water loss still exists, as the saturation deficit of the air contributes to transpiration through the plant cuticule. It amounts to less than $10 \%$ of the daytime volume in the present situation (summer conditions).

\subsection{Kinetics of mineral uptake}

Experimental setup: 16 rose plants are placed in series in a length of guttering continuously fed with recycled nutrient solution from a 4 liter tank. Two selective probes from a Tacussel Ama 220 apparatus measure the nitrate and the potassium concentrations in the stream. Values are recorded every $10 \mathrm{mn}$. A correction is made to account for the temperature of the solution.

The differential signal corrected for water uptake by the plant provides a measure of its mineral absorption. The pattern of nitrate ion uptake over a sequence of 4 consecutive days is shown in Figure 2, together with total radiation and solution temperature (in equilibrium with the air).

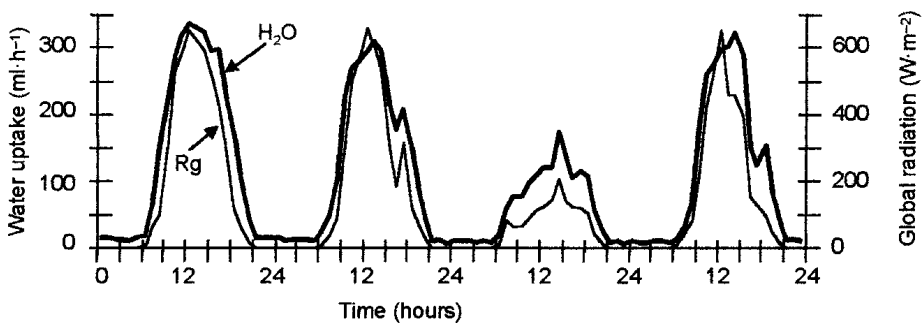

Figure 1. Water uptake $\left(\mathrm{H}_{2} \mathrm{O}\right.$ in $\left.\mathrm{ml} \cdot \mathrm{h}^{-1}\right)$ and solar radiation $\left(\mathrm{R}_{\mathrm{g}}\right.$ in $\left.\mathrm{W} \cdot \mathrm{m}^{-2}\right)$ over 4 successive days. 


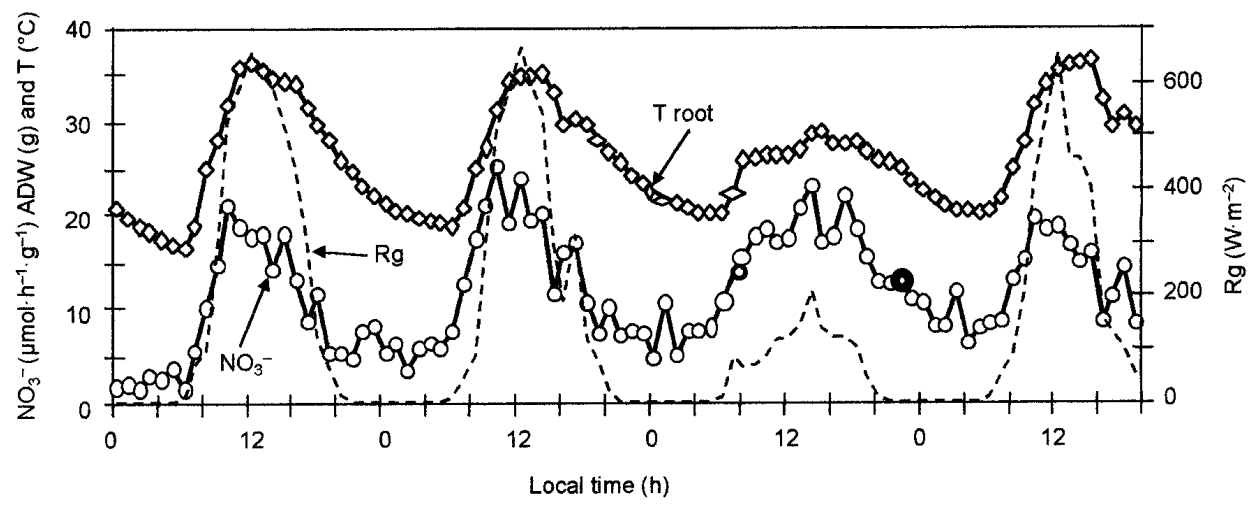

Figure 2. $\mathrm{NO}_{3}{ }^{-}$absorption $\times 10\left(\right.$ in $\mu \mathrm{mol} \cdot \mathrm{h}^{-1} \cdot \mathrm{g}^{-1}$ Aerial Dry Weight), root liquid medium temperature (in ${ }^{\circ} \mathrm{C}$ ) and solar radiation (in $\mathrm{W} \cdot \mathrm{m}^{-2}$ ) on 4 consecutive days.

\subsection{Discussion of experimental results}

The main feature observed in these experiments is the nearly perfect synchronism between water or mineral uptake and the solar radiation $\mathrm{R}_{\mathrm{g}}$. The second most obvious feature is the fact that nitrate uptakes do not stay proportional to the total solar radiation: this can be easily seen from the curve observed on day 3 , when the radiation is only $1 / 4$ of what it was the day before, while mineral absorption is barely reduced. On a given sunny day, the same effect can be observed between early or late hours on a given day (when total radiation levels are low) compared to midday: only a moderate increase of the absorption rate is found for much stronger radiation levels. By closely looking at the daily absorption pattern, a third feature can be noticed: a symmetrical total radiation curve around solar noon does not deliver a symmetrical curve for mineral uptake. The mineral absorption is lower in the afternoon. This asymmetry also affects the temperature curve, as a well known thermal inertia effect. A final feature is the progressive increase of nitrate absorption rates at night over successive days which follows the steady rise of night temperatures.

\section{Modelling}

\subsection{Plant transpiration}

Plant water requirements correspond on a short term basis to passive evaporation of the osmotic water fraction of the plant through its leaf surface. The driving force is the gradient of water vapor pressure from the saturated substomatal cavities to the outside of the convective leaf boundary layer [3]. The usual hypothesis is to assume complete similarity between convective heat transfers (coefficient $\mathrm{h}_{\mathrm{cv}}$, in W. $\mathrm{m}^{-2}{ }^{\circ} \mathrm{C}$ ) and mass transfers (coefficient $\mathrm{h}_{\mathrm{m}}$, in $\mathrm{kg} \cdot \mathrm{m}^{-2} \cdot \mathrm{s}^{-1}$ ), which is expressed by the Lewis approximation:

$$
\mathrm{h}_{\mathrm{m}}^{\mathrm{ex}}=\frac{\mathrm{h}_{\mathrm{cv}}^{\mathrm{ex}}}{\mathrm{C}_{\mathrm{p}}}
$$

where $\mathrm{C}_{\mathrm{p}}$ is the specific heat capacity of air at constant pressure.

When $\mathrm{E}_{\mathrm{TR}}$ expresses the transpiration rate in energy units, it reads

$$
\mathrm{E}_{\mathrm{TR}}=\mathrm{h}_{\mathrm{m}} \cdot \mathrm{Lv} \cdot\left(\mathrm{w}_{\mathrm{sat}}\left(\mathrm{T}_{\mathrm{f}}\right)-\mathrm{w}_{\mathrm{a}}\right)
$$


where $\mathrm{Lv}$ is the evaporation enthalpy, in $\mathrm{J} \cdot \mathrm{kg}^{-1}$ and $\mathrm{w}_{\mathrm{a}}$ (respectively $\mathrm{w}_{\text {sat }}$ ) is the absolute humidity (respectively at saturation), in $\mathrm{kg} / \mathrm{kg}$ of dry air.

$\mathrm{h}_{\mathrm{m}}{ }^{-1}$ here stands for the total resistance, the sum of the stomatal resistance $r_{s}$ and the boundary layer resistance $\mathrm{r}_{\mathrm{ex}}=\left(\mathrm{h}_{\mathrm{m}}^{\mathrm{ex}}\right)^{-1}$.

To make equation (2) linear in $\mathrm{T}_{\mathrm{f}}$, it is customary to replace (after Monteith [3]) the saturation curve of $\mathrm{w}_{\text {sat }}$ by its local tangent at $\mathrm{T}_{\mathrm{f}}$. This introduces its slope coefficient $\mathrm{A}_{\text {sat }}$.

Once this is done, it is possible to eliminate $T_{f}$ by using the heat balance equation for the leaf:

$$
\mathrm{R}_{\mathrm{n}}=\mathrm{E}_{\mathrm{TR}}+\mathrm{h}_{\mathrm{cv}}^{\mathrm{ex}}\left(\mathrm{T}_{\mathrm{f}}-\mathrm{T}_{\mathrm{a}}\right)
$$

where $R_{n}$ is the net radiation on the leaf. This finally gives:

$$
\mathrm{E}_{\mathrm{TR}}=\mathrm{R}_{\mathrm{n}}-\frac{\mathrm{h}_{\mathrm{cv}}^{\mathrm{ex}}}{\frac{\mathrm{A}_{\mathrm{sat}} \cdot \mathrm{Lv}}{\mathrm{r}_{\mathrm{s}}+\frac{\mathrm{C}_{\mathrm{p}}}{\mathrm{h}_{\mathrm{cv}}^{\mathrm{ex}}}+\mathrm{h}_{\mathrm{cv}}^{\mathrm{ex}}}}\left(\mathrm{R}_{\mathrm{n}}-\frac{\mathrm{Lv} \cdot \mathrm{D}_{\mathrm{a}}}{\mathrm{r}_{\mathrm{s}}+\frac{\mathrm{C}_{\mathrm{p}}}{\mathrm{h}_{\mathrm{cv}}^{\mathrm{ex}}}}\right) .
$$

This expression exhibits an apparent linear dependance of $E_{T R}$ on the net incident radiation $R_{n}$ and on the air saturation deficit $\mathrm{D}_{\mathrm{a}}$, but the proportionality coefficients are far from being constant: they are implicit functions of the ambient temperature $\mathrm{T}_{\mathrm{a}}$ through $\mathrm{A}_{\mathrm{sat}}$ and $\mathrm{h}_{\mathrm{cv}}^{\mathrm{ex}}$, and may be dependent on other climatic or edaphic conditions through $\mathrm{r}_{\mathrm{s}}$.
It is important to correctly account for the variation of these coefficients throughout the day: the term Asat can nearly double when the temperature of the air rises from $15{ }^{\circ} \mathrm{C}$ to $25^{\circ} \mathrm{C}$. The net radiation $R_{n}$ is conveniently equated to the incident radiation on the plant canopy, because leaf temperatures and the temperature of the greenhouse cover stay relatively close in normal circonstances (they behave like both ends of a heat pipe). Provided no extreme climatic condition takes place, and for a well managed irrigation, it is reasonable to assume that the stomatal resistance stays constant during the day (at least when net solar radiation $\mathrm{R}_{\mathrm{n}}$ exceeds $50 \mathrm{~W} / \mathrm{m}^{2}$ ). With such an hypothesis, equation (4) offers a precise estimate of actual transpiration rates of a plant free of stress. If the temperature and the humidity of the air were to stay constant in the greenhouse during the day (Fig. 3), the resulting water flux would be nearly proportional to the incident solar radiation $\mathrm{Rg}$, as suggested by the following figure (Fig. 4)

\subsection{Kinetics of mineral uptake}

Unlike water, most mineral elements are absorbed by the plant through active processes. This can be expressed as the effect of some ionic pump of flow rate per unit plant mass $\mathrm{P}_{\mathrm{o}}$. In opposition to this active uptake, there is a passive diffusion process through the root epiderm: this creates a leak flux $Q_{L}$ from high concentration to low concentration regions. An assimilation flux $\mathrm{Q}_{\mathrm{as}}$ converts minerals absorbed by the plant into organic

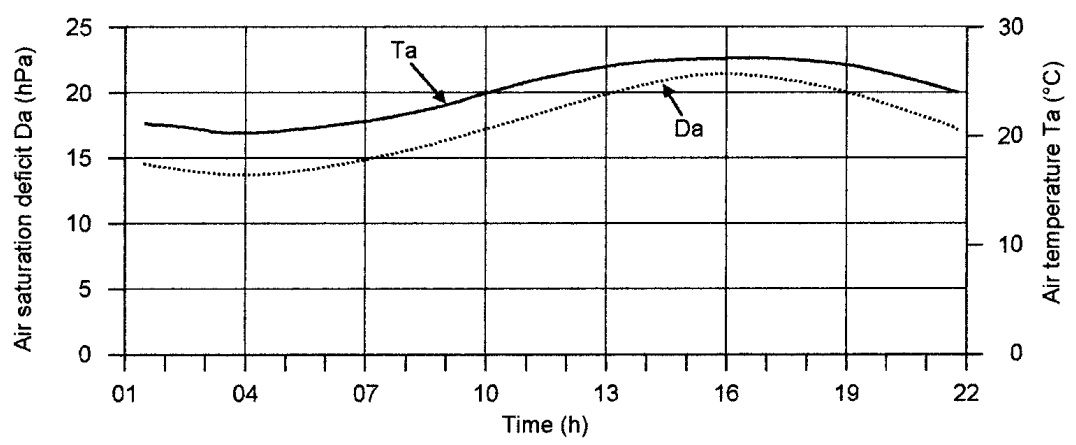

Figure 3. Air saturation deficit $D_{a}$ and temperature $\mathrm{T}_{\mathrm{a}}$ variation in $\mathrm{a}$ day. 


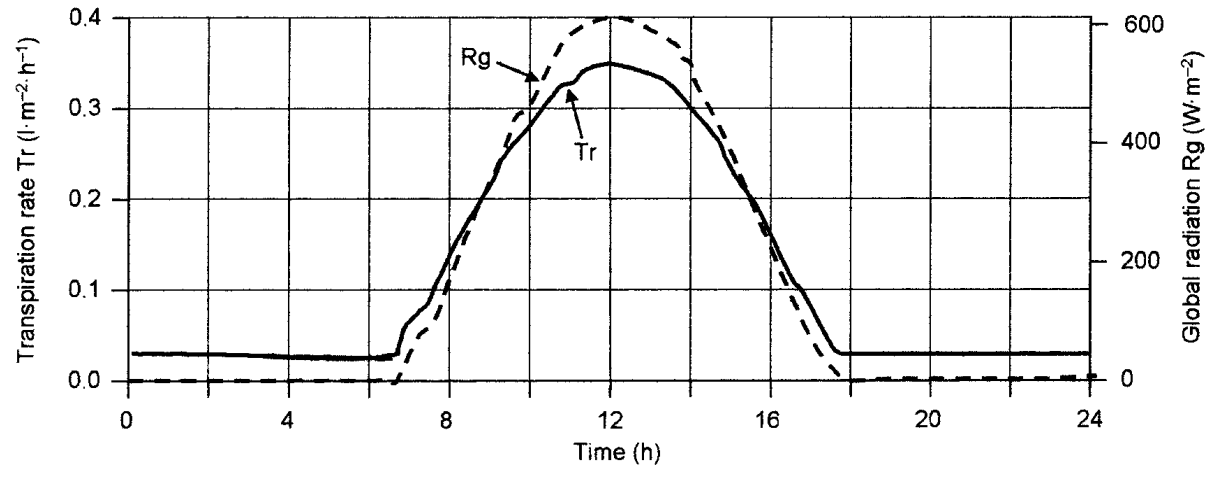

Figure 4. Incident radiation $\mathrm{R}_{\mathrm{g}}$ and transpiration rate $\mathrm{T}_{\mathrm{r}}$ on a sunny day.

matter under the influence of solar energy. These effects can be linked together to make a simplified "pump-leak-buffer model" as formulated by Scaife [8] for the concentration $\mathrm{C}$ of a given mineral in the sap.

$$
\frac{\mathrm{dC}}{\mathrm{dt}}+\mathrm{Q}_{\mathrm{L}}+\mathrm{Q}_{\mathrm{as}}=\mathrm{P}_{\mathrm{o}}
$$

Following Scaife, it can be argued that the ionic pump should be able to ensure a $50 \%$ increase of fresh matter in one day. Assuming that a rose plant has $90 \%$ water content and that nitrogen amounts to $3 \%$ of the dry matter, it is possible to estimate the intensity of the pump, and express it as a function of the volume of osmotic water of the plant (here $70 \%$ of the total water). This gives:

$$
P_{o}=0,1 \mathrm{~g} \cdot \mathrm{N} / \mathrm{dm}^{3} / \mathrm{h} \text {. }
$$

The diffusion constant responsible for mineral efflux from the plant to the outside medium can be evaluated from an hypothetical situation when the mineral uptake by the plant is vanishing (a situation with zero incident solar radiation after a long night). We then refer to the composition of the raw sap in the plant, as measured on exudates from cut stems. The observed nitrate content on rose exudates is of the order of $10 \mathrm{mmol} \cdot \mathrm{L}^{-1}$ [7].

This means that the maximum concentration gradient, responsible for balancing the ionic pump, is less or equal to $10 \mathrm{mmol} \cdot \mathrm{L}^{-1}$.
This suggests a diffusion coefficient $K=0.7 \mathrm{~h}^{-1}$ for $\mathrm{Q}_{\mathrm{L}}$

$$
\mathrm{Q}_{\mathrm{L}}=\mathrm{K}\left(\mathrm{C}_{\mathrm{m}}-\mathrm{C}_{\mathrm{o}}\right)
$$

where $C_{m}$ is the nitrate concentration (per unit plant mass) in the plant, and $\mathrm{C}_{\mathrm{o}}$ the concentration in the substrate.

- Assimilation flux $\mathrm{Q}_{\mathrm{as}}$

After Morisot [7], it is reasonable to estimate that rose plants produce $2 \mathrm{~g}$ of dry matter for a cumulative incident radiation $\mathrm{R}_{\mathrm{g}}$ of 1 MJ-PAR. Converting $1 \mathrm{kWh} / \mathrm{m}^{2}$ of total incident radiation $\mathrm{R}_{\mathrm{g}}$ into $1.8 \mathrm{MJ}-\mathrm{PAR} / \mathrm{m}^{2} \cdot \mathrm{h}$.

This allows $\mathrm{Q}_{\mathrm{as}}$ to be expressed in $\mathrm{mg} \cdot \mathrm{N} / \mathrm{dm}^{3} \cdot \mathrm{h}$, as a function of $\mathrm{R}_{\mathrm{g}}$ :

$$
\mathrm{Q}_{\mathrm{as}}=\mathrm{F} \cdot \mathrm{R}_{\mathrm{g}}
$$

with a coefficient $\mathrm{F}$ of the order 100 with such units.

\subsection{Analytical resolution}

It is possible to get a direct analytical solution of equation (5) when the time dependant term $R_{g}$ is represented by a simple trigonometric function. This can be considered as the first term of a Fourier decomposition of the total radiation $\mathrm{R}_{\mathrm{g}}$ during a sequence of identically sunny days:

$$
\mathrm{R}_{\mathrm{g}}=\frac{1}{2} \mathrm{R}_{\mathrm{g} \max } \cdot[1-\cos (\mathrm{wt})]
$$


where $\omega$, equal to $2 \pi / 24 \mathrm{~h}^{-1}$ is the pulsation of $\mathrm{R}_{\mathrm{g}}$ in $\mathrm{h}^{-1}$.

Then, the solution reads as:

$$
\mathrm{C}(\mathrm{t})=\frac{\mathrm{A}}{\mathrm{K}}+\mathrm{C}_{0} \mathrm{e}^{-\mathrm{Kt}}+\lambda \cdot \cos (\omega \mathrm{t}-\varphi) .
$$

After transient behavior, the solution becomes periodic and fluctuates around a mean value equal to $\mathrm{A} / \mathrm{K}$, where $\mathrm{A}=\mathrm{K} \mathrm{C}_{\mathrm{o}}-\mathrm{F} \mathrm{R}_{\mathrm{gmax}} / 2+\mathrm{P}_{\mathrm{o}}$.

The critical parameters are the time constant for the decay: $\tau=(\log 2) / K$, and the phase shift $\varphi$ which is given by

$$
\varphi=\arctan \left(\frac{\omega}{\mathrm{K}}\right) .
$$

The constant $\lambda$ is given by:

$$
\lambda=\frac{1}{2} \frac{\mathrm{F} \cdot \mathrm{R}_{\mathrm{g} \max }}{\sqrt{\mathrm{K}^{2}+\omega^{2}}}
$$

\subsection{Application to actual measurements on the NFT tank}

Successive measurements of the nitrate concentration and the volume of the recycled solution enable calculation of the plant mineral uptake over successive time intervals.

The proper equation for the NFT tank nitrate content denoted by $\mathrm{N}$ is:

$$
\frac{\mathrm{dN}}{\mathrm{dt}}=\mathrm{P}_{0}-\mathrm{K}\left(\mathrm{C}-\mathrm{C}_{\mathrm{m}}\right)=\frac{\mathrm{dC}}{\mathrm{dt}}+\mathrm{Q}_{\mathrm{as}}
$$

in which $\mathrm{C}$ is replaced by its expression from (10):

$$
\begin{aligned}
& \frac{d N}{d t}=\frac{1}{2} F \cdot R_{g \max }(1+\cos \omega t)-K \cdot C_{0} \cdot e^{-K t} \\
& +a \omega \cdot \cos (\omega t)-b \omega \cdot \sin (\omega t)
\end{aligned}
$$

which can be rewritten as:

$$
\begin{aligned}
& \frac{\mathrm{dN}}{\mathrm{dt}}=\frac{1}{2} \mathrm{~F} \cdot \mathrm{R}_{\mathrm{g} \max }-\mathrm{K} \cdot \mathrm{C}_{0} \cdot \mathrm{e}^{-\mathrm{Kt}} \\
& +\mathrm{K} \cdot \lambda \cdot \cos (\omega \mathrm{t}-\varphi) .
\end{aligned}
$$

This solution can again be analysed as a transitory behavior tending to a purely sinusoidal signal after a decaying delay equal to $\tau=\frac{3}{\mathrm{~K}}$. The periodic behavior exhibits the same phase shift $\varphi$ as before, which implies a time shift in the absorption peak equal to:

$$
\Delta \mathrm{t}=\frac{12}{\pi} \cdot \arctan \left(\frac{\pi}{12 \mathrm{~K}}\right) .
$$

The relationship between this time shift and the decaying delay reads as:

$$
\tau=\frac{36}{\pi} \cdot \tan \left(\frac{\pi}{12} \cdot \Delta \mathrm{t}\right) .
$$

This relationship is useful to identify any memory effect in the absorption curve of a given day from the previous day: the time shift must exceed 3 hours for $\Delta \mathrm{t}$ to be larger than 12 hours and imply a memory from the previous evening to the next morning.

Another characteristic of the absorption curves can provide information on such delays: the ratio of night-time absorption to the total fluctuation amplitude. The ratio is expressed as

$$
\frac{\Phi_{\text {noc }}}{\Phi_{\text {diu }}-\Phi_{\text {noc }}}=\frac{1}{2} \sqrt{1+\frac{\omega^{2}}{\mathrm{~K}^{2}}}
$$

and is directly related to the value of $\mathrm{K}$.

In the case of ryegrass, this ratio is close to unity, which is consistent with a value of $\mathrm{K}$ smaller than $w$. But in the case of rose, the ratio is smaller than unity and implies a value of $\mathrm{K}$ close to unity. The consequence is that time shifts in the absorption curves are smaller for rose plants than for ryegrass (less than 1 hour instead of 4 hours). This proves that memory effects coming from the decaying delay cannot exceed 4 hours in rose plants: the PLB model percludes any effect from one day to the next day. As a consequence, the absorption curve should be nearly proportional to the total radiation curve. In fact, a detailed analysis of the absorption curves from [5] shows that there 
is no evidence of any significant phase shift between the total radiation signal and the absorption signal: they both rise quite simultaneously in the morning.

On the other hand, the absorption stops increasing linearly with the radiation beyond a threshold: a saturation effect seems to take place beyond $300 \mathrm{~W} / \mathrm{m}^{2}$ in the case of a low leaf area index.

Concerning the temperatures, two opposite effects tend to show up: slowly rising night temperatures of the nutrient solution, below $25^{\circ} \mathrm{C}$, clearly favor mineral absorption at night. But excessive temperatures during daytime (beyond $30^{\circ} \mathrm{C}$ ), act as an inhibitor for mineral absorption.

The inhibition by excessive temperatures after noon should not be interpreted as a phase shift in the absorption curve, and it is possible to modify the PLB model to include such effects.

\subsection{Modification of the PLB model}

a) One replaces the constant strength $P_{o}$ of the pump term by a strength which slowly increases with temperatures

$$
\mathrm{P}^{\prime}=\mathrm{P}_{\mathrm{o}}+\mathrm{I}_{1} \cdot \mathrm{f}(\mathrm{T})
$$

where $I_{1}$ is a constant and $\mathrm{f}(\mathrm{T})$ is a proportional to T below $20^{\circ} \mathrm{C}$;

b) The progressive saturation effect for excessive radiation $R_{g}$ is accounted for by a logarithmic law instead of the plain proportionality law.

c) An exponentially decreasing law is introduced for the temperature dependance.

Altogether, these modifications amount to replacing the assimilation term $\mathrm{Q}_{\mathrm{as}}$ by:

$$
\mathrm{Q}_{\mathrm{as}}^{\prime}=\mathrm{I}_{0} \cdot \ln \left(1+\frac{\mathrm{R}_{\mathrm{g}}}{100}\right) \cdot \mathrm{e}^{-\frac{\mathrm{T}-20}{40}}
$$

where $\mathrm{I}_{0}$ is a constant.

The balance equation reads as before:

$$
\frac{\mathrm{dC}}{\mathrm{dt}}=\mathrm{P}^{\prime}-\mathrm{Q}_{\mathrm{f}}-\mathrm{Q}_{\mathrm{as}}^{\prime} \text {. }
$$

Because of the modifications, the method of solution must now be numerical. This will allow real meteorological conditions to be tested here, simulated by simple analytical laws.

Two typical weather conditions were simulated: a sunny day and a overcast day, as shown below (Fig. 5).

Night temperatures were assumed to be steadily rising, from $15^{\circ} \mathrm{C}$ to $20^{\circ} \mathrm{C}$, as shown in Figure $5 \mathrm{c}$. Radiation law $\mathrm{R}_{\mathrm{g}}$ is directly reproduced from the observed data (Fig. 6).

The Runge-Kutta method is used to solve the equation numerically for the nitrate concentration. The result shows that the MPLB model is able to account for the small variation of the absorption between the two types of weather conditions (Fig. 6): on the third day, the sudden radiation decrease is indeed partly compensated by the temperature drop which prevents the inhibition effect from taking place.

The computed values for the absorbed nitrate flux (Fig. 6) are in fair agreement with the observed values (Fig. 2) if we take into account the fact that the scales of flux in the two figures can be compared taking into account that fluxes in $\mathrm{mg} / \mathrm{h} / \mathrm{dm} 3$ may be approximatively expressed in $\mu \mathrm{mol} / \mathrm{h} / \mathrm{g}$ after division by 10 (for more explanations see [5]).

The modified PLB model is therefore able to justify the absorption rate on the cloudy day (only weakly affected by the drop in the total radiation level). This explanation does not involve any memory effect from the previous sunny day, but simply states that plant mineral uptakes are far from being proportional to the radiation level.

Now, it would be interesting to observe two consecutive cloudy days, following a sequence of sunny days, to confirm that no memory effect applies either to the 4th day: the modified PLB model would predict two identical absorption curves; on the contrary, a theory implying a 48 hour plant memory would predict different absorption curves for the two successive cloudy days.

The last step is to combine the PM transpiration model, giving the water uptake rate, and the 

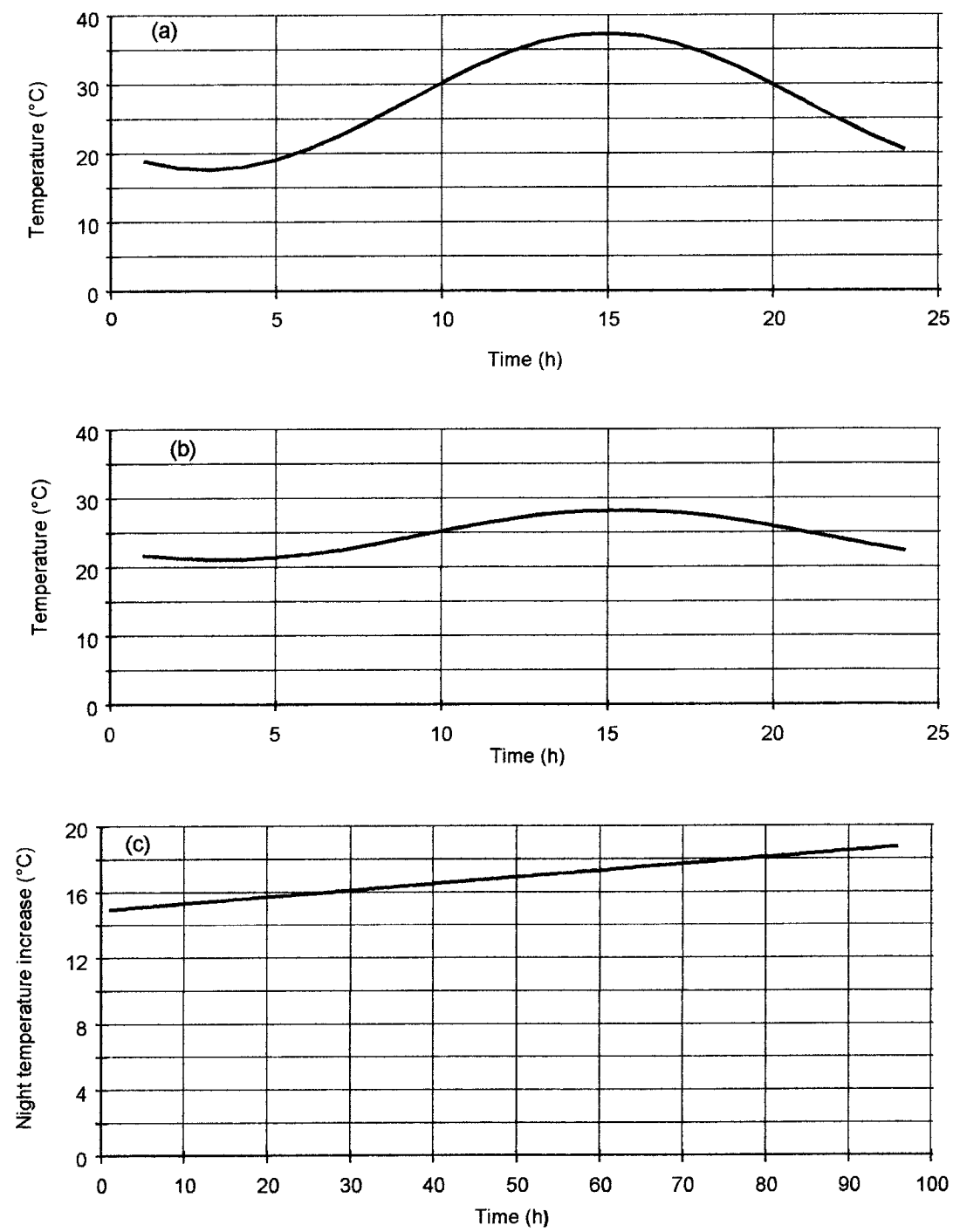

Figure 5. a. Simulated daily temperature swing of the root medium on a sunny day. b. Simulated daily temperature swing of the root medium on a cloudy day. c. Simulated night temperature increase in the root medium.

modified PLB model, to compute the absorption concentration of the plant through a 24-hour cycle: the concentration of the absorbed nutrient solution entering the root volume is simply the ratio of the mineral flux (from PLB) to the water flux (from $\mathrm{PM})$. This concept of absorption concentration is particularly important in soilless cultures, because it is the reference for the composition of the nutrient solution provided to the medium by the drippers. Any discrepancy between the composition of the incoming solution and the solution absorbed by the roots results in some imbalance in the medium and concentrations gradients close to the root surface. The computed absorption concentration obtained from the present models is shown in Figure 7.

It is clear that the fluctuations of the absorbed concentration are very large over a 24-hour cycle. 

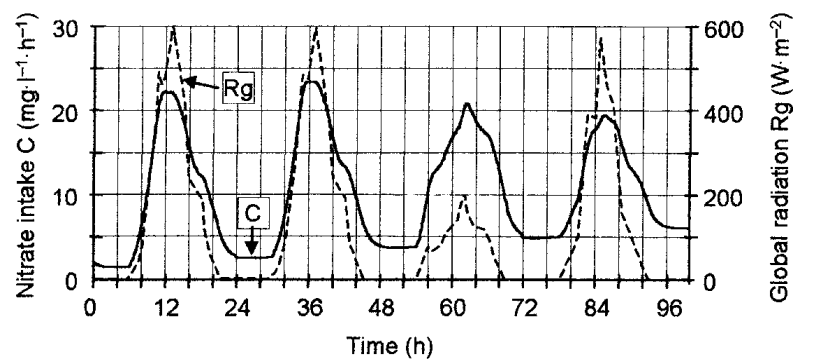

Figure 6. Simulated nitrate intake rates $\mathrm{C}$ compared to observed incident radiation $R_{g}$.

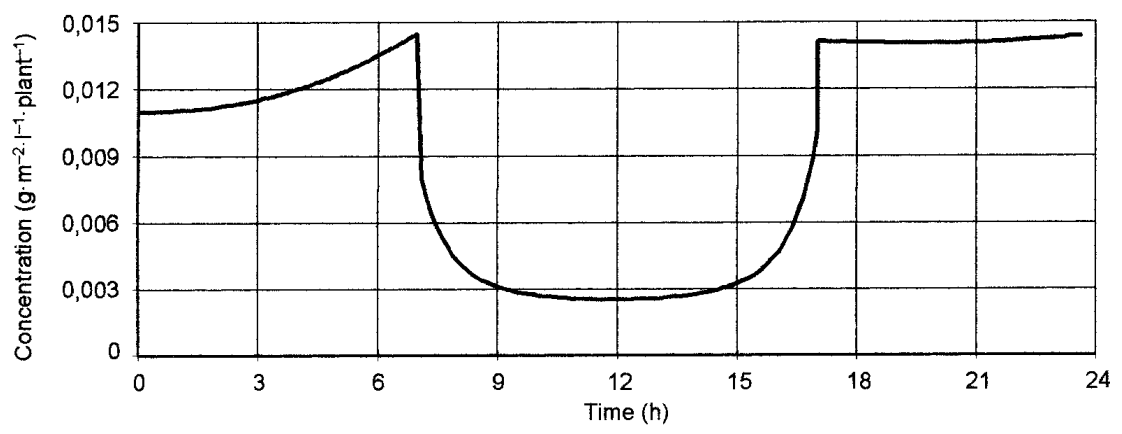

Figure 7. Variation of the nitrate absorption-concentration of the plant on a sunny day.

Therefore, there is a great probability that the medium will not be in phase with the demand and that some mineral accumulation will occur around the root system during a sunny day. The real challenge is to be able to match in time the demand and the chemical composition of the medium.

\section{Conclusion}

Scaife's MPLB model, adapted to a rose species and corrected for temperature excess and radiative saturation, accurately reproduces the absorption curves observed under various climatic conditions. When associated with the classical PM model for plant transpiration, it enables the actual nitrate absorption-concentration of a rose plant at any time in a day to be predicted, and can be used to manage, on a short time basis, the fertigation in soilless cultural systems using porous substrates, with the opportunity to avoid temporary salinity increases during daytime.

\section{References}

[1] Baille M., Baille A., Delmon D., Microclimate and transpiration of greenhouse rose crops, Agric. For. Meteorol. 71 (1994) 83-97.

[2] Bougoul S., Étude d'écoulements salins dans des milieux fibreux saturés utilisés en substrats de culture, Thèse de Doctorat en Sciences, Université de Nice, 1996.

[3] Boulard T., Baille A., Lagier J., Mermier M., Vilette F., Mesures et modélisation de la résistance stomatique foliaire et de la transpiration d'un couvert de tomates de serre, Agronomie 11 (1991) 259-274.

[4] Boulard T., Jemaa R., Greenhouse tomato crop transpiration, application to irrigation control, Acta Hort. 335 (1993) 381-387.

[5] Brun R., Chazelle L., Water and nitrate $\left(\mathrm{NO}_{3}\right)$ absorption kinetics in the nycthemeral cycle of Rosa 
hybrida grown in greenhouse in recirculation solution, Plant Nutr. 19 (1996) 1.

[6] Davies W.J., Zhangs J., Root signals and the regulation of growth and development of plants in drying soil, Annu. Rev. Plant Physiol. Plant Mol. Biol. 42 (1991) 55-76.

[7] Morisot A., "PP. Rose": an empirical model to predict the potential yield of cut roses, Acta Hort. 424 (1996) 87-93.
[8] Scaife A., A pump/leak/ buffer model for plant nitrate uptake, Plant and Soil 114 (1989) 139-141.

[9] Tardieu F., Davies W.J., Stomatal response to abscissic acid is a function of current plant water status, Plant Physiol. 98 (1992) 540-545.

[10] Urban L., Jaffrin A., Brun R., Control of salinity in the rhizosphere of plants grown in soilless medium, Acta Hort. 408 (1995) 73-79. 